PICTURE OF THE MONTH

\title{
HDlive Flow with Spatiotemporal Image Correlation for Assessment of Fetal Goiter
}

\author{
Toshiyuki Hata ${ }^{1}$, Riko Takayoshi ${ }^{2}$, Takahito Miyake ${ }^{3}$, Nobuhiro Mori ${ }^{4}$, Kenta Yamamoto ${ }^{5}$, Kosuke Koyano ${ }^{6}$, Takashi Kusaka ${ }^{7}$,
} Kenji Kanenishi ${ }^{8}$

\begin{abstract}
Case description: We present our experience of diagnosing fetal goiter using radiant flow and HDlive flow with spatiotemporal image correlation (STIC). A 39-year-old pregnant Japanese woman, gravida 3, para 1, with Graves' disease was referred to our ultrasound clinic at 37 weeks and 1 day of gestation because of suspected fetal goiter. Two-dimensional (2D) sonography revealed enlarged thyroid glands (left lobe, $29.5 \times$ $22 \mathrm{~mm}$; right lobe, $32.9 \times 21.2 \mathrm{~mm}$ ). Radiant flow showed abundant blood flow on both lobes. HDlive flow with STIC clearly demonstrated spatial relationships of pulsatile dilated blood vessels in the fetal goiter. Our results suggest that HDlive flow with STIC shows precise spatial vascularity with pulsation of fetal goiter in utero.
\end{abstract}

Keywords: 3D ultrasound, Fetal goiter, HDlive flow, Radiant flow, Spatiotemporal image correlation.

Donald School Journal of Ultrasound in Obstetrics and Gynecology (2020): 10.5005/jp-journals-10009-1616

\section{INTRODUCTION}

Radiant flow is a novel form of color Doppler that generates threedimensional (3D) data to produce a two-dimensional (2D) gray-scale image utilizing shading determined by the color Doppler signal's amplitude. ${ }^{1}$ HDlive flow is made of 3D color Doppler with an adjustable light source to realize lighting and shadowing effects, which means that depth perception is possible on fetal 3D blood flow examination. ${ }^{2}$

Several reports are available on the antenatal diagnosis of fetal goiter using 2D color/power and 3D power Doppler ultrasound; ${ }^{3-6}$ however, to the best of our knowledge, this is the first report on HDlive flow with spatiotemporal image correlation (STIC) for the prenatal diagnosis of fetal goiter.

\section{Case Description}

A 39-year-old pregnant Japanese woman, gravida 3, para 1, with Graves' disease was referred to our ultrasound clinic at 37 weeks and 1 day of gestation because of suspected fetal goiter (Fig. 1).

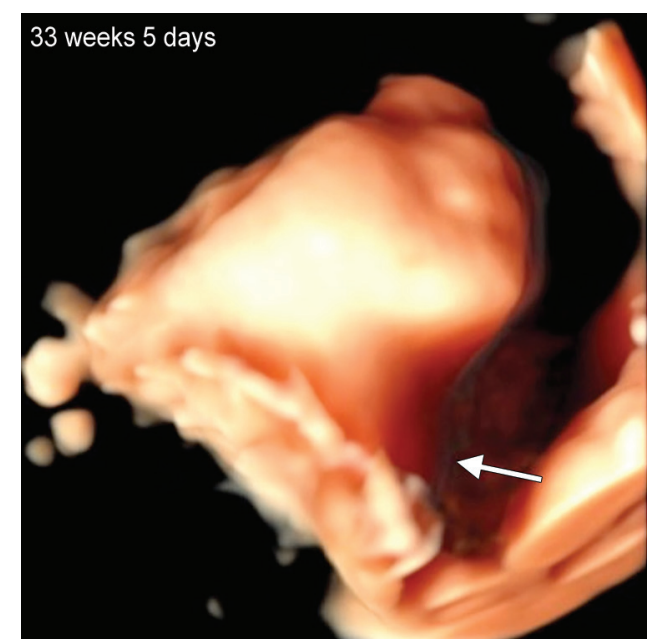

Fig. 1: HDlive image of fetal neck at 33 weeks and 5 days of gestation. Fetal neck swelling (arrow) is noted \begin{tabular}{l}
\hline 1,3Department of Perinatology and Gynecology, Kagawa University \\
Graduate School of Medicine, Kagawa, Japan; Department of \\
Obstetrics and Gynecology, Miyake Clinic, Okayama, Japan \\
2Department of Obstetrics and Gynecology, Miyake Clinic, Okayama, \\
Japan \\
4,5,8Department of Perinatology and Gynecology, Kagawa University \\
Graduate School of Medicine, Kagawa, Japan \\
6,7Department of Pediatrics, Kagawa University Graduate School of \\
Medicine, Kagawa, Japan \\
Corresponding Author: Toshiyuki Hata, Department of Perinatology \\
and Gynecology, Kagawa University Graduate School of Medicine, \\
Kagawa, Japan; Department of Obstetrics and Gynecology, Miyake \\
Clinic, Okayama, Japan, Phone: +81 (0)87-891-2174, e-mail: toshi28@ \\
med.kagawa-u.ac.jp
\end{tabular}

How to cite this article: Hata T, Takayoshi R, Miyake T, et al. HDlive Flow with Spatiotemporal Image Correlation for Assessment of Fetal Goiter. Donald School J Ultrasound Obstet Gynecol 2020;14(1):1-3.

Source of support: Nil

Conflict of interest: None

She has been treated with levothyroxine sodium hydrate, potassium iodide, and propylthiouracil, and her thyroid status was euthyroid. The 2D sonography revealed enlarged thyroid glands (left lobe, $29.5 \times 22 \mathrm{~mm}$; and right lobe, $32.9 \times 21.2 \mathrm{~mm}$ ) (Fig. 2). The fetal trachea was not compressed by either lobe. Radiant flow showed abundant blood flow on both lobes, especially on the left lobe (Fig. 3). HDlive flow with STIC clearly demonstrated precise spatial relationships of pulsatile dilated blood vessels in the fetal goiter (Fig. 4).

Elective cesarean section was performed on the next day ( 37 weeks and 2 days), and a female infant weighing $2811 \mathrm{~g}$ was delivered with an umbilical artery $\mathrm{pH}$ of 7.348 and Apgar score of $8 / 9$ at 1 minute and 5 minutes, respectively. Thyroid-stimulating hormone (TSH), FT3, and FT4 levels in the cord blood were $203.7 \mu \mathrm{IU} / \mathrm{mL}$ (0.35 to 3.73 ), $2.71 \mathrm{pg} / \mathrm{mL}$ (2.2 to 4.1 ), and $0.54 \mathrm{ng} / \mathrm{mL}$ (0.88-1.81), respectively. Neonatal goiter was confirmed (Fig. 5),

(c) The Author(s). 2020 Open Access This article is distributed under the terms of the Creative Commons Attribution 4.0 International License (https://creativecommons. org/licenses/by-nc/4.0/), which permits unrestricted use, distribution, and non-commercial reproduction in any medium, provided you give appropriate credit to the original author(s) and the source, provide a link to the Creative Commons license, and indicate if changes were made. The Creative Commons Public Domain Dedication waiver (http://creativecommons.org/publicdomain/zero/1.0/) applies to the data made available in this article, unless otherwise stated. 


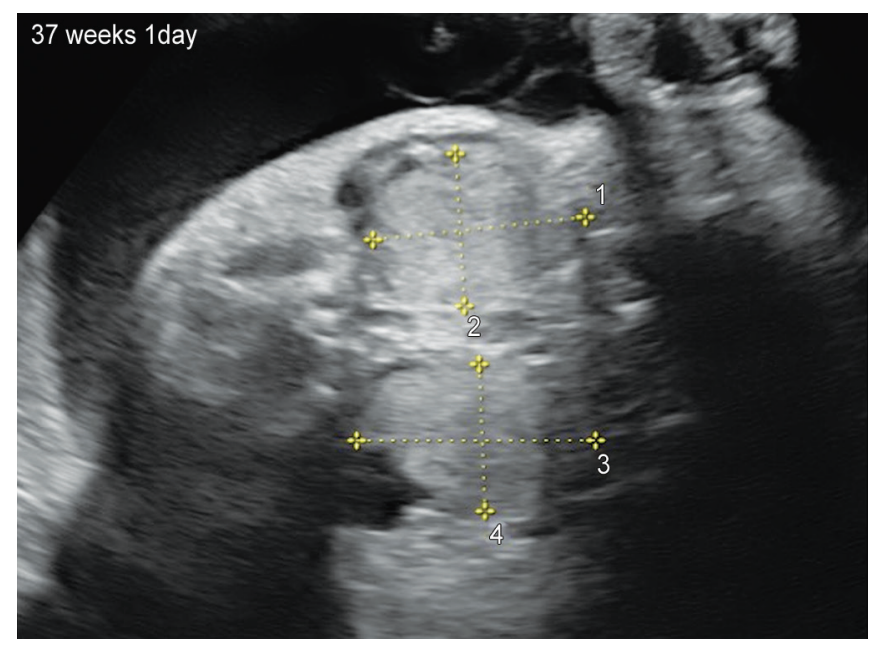

Fig. 2: Transverse two-dimensional sonographic image of fetal neck at 37 weeks and 1 day of gestation. Enlarged thyroid glands (left lobe, $29.5 \times 22 \mathrm{~mm}$; and right lobe, $32.9 \times 21.2 \mathrm{~mm}$ ) are noted. Fetal trachea is not compressed by either lobe

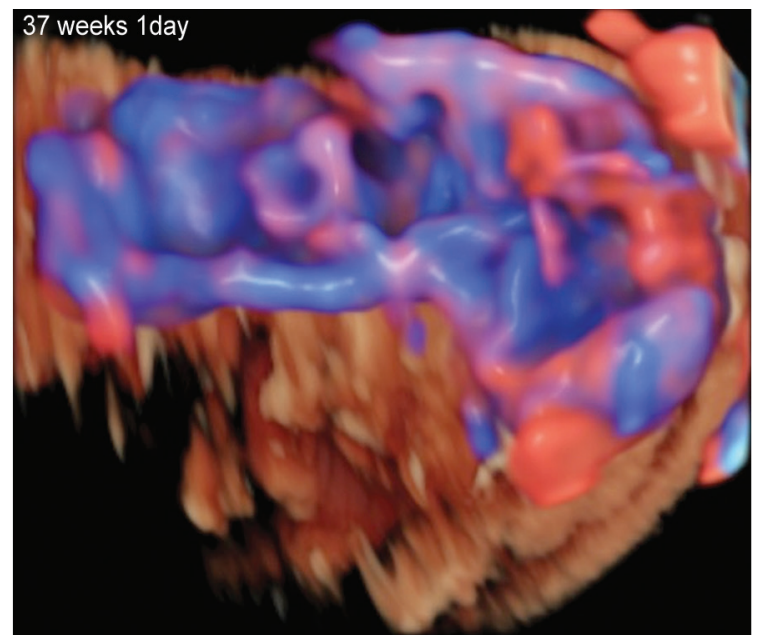

Fig. 4: Precise spatial relationships of pulsatile dilated blood vessels in the fetal goiter are clearly depicted with HDlive flow with spatiotemporal image correlation at 37 weeks and 1 day of gestation

and levothyroxine sodium hydrate was administered for 3 days. On the first neonatal day, atrial flutter (200-230 bpm) was noted. Electrical defibrillation with 2 joules was performed and the atrial flutter disappeared. Thereafter, the neonate showed a favorable course. The mother also followed a favorable course after delivery.

\section{Discussion}

A unique characteristic of fetal goiter is the rich vascularity of the thyroid gland..$^{3,4}$ In our case, radiant flow clearly showed abundant blood flow in the fetal goiter using the 3D color Doppler information on a 2D grayscale image. Only two reports are available regarding the $3 \mathrm{D}$ power Doppler ultrasound diagnosis of fetal goiter. ${ }^{5,6}$ However, spatial relationships of the vascularity of fetal goiter were still poor. In this study, HDlive flow with STIC clearly demonstrated precise spatial relationships of dilated thyroid blood vessels in real-time. HDlive flow with STIC was a useful diagnostic modality for the assessment of congenital heart anomaly, especially

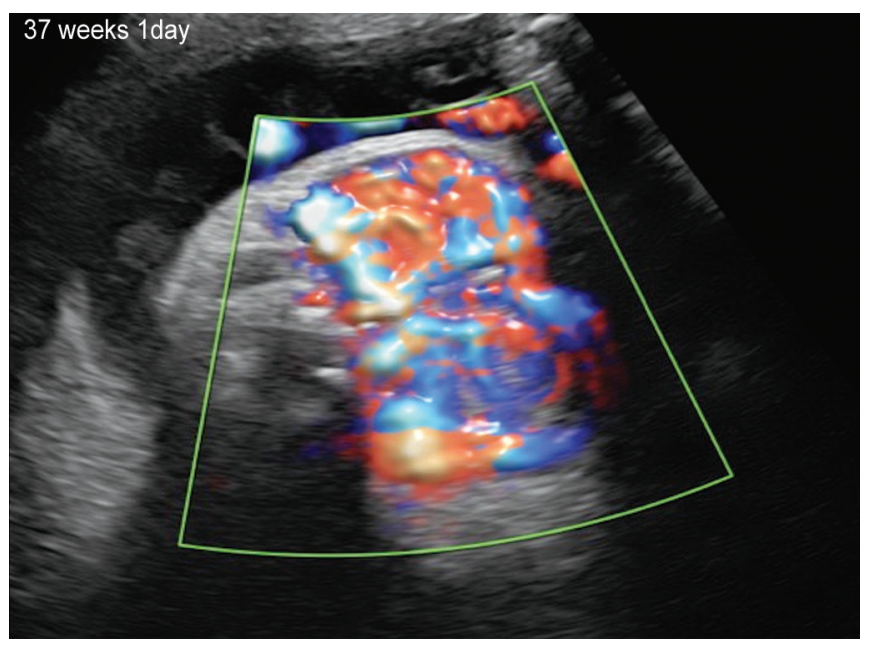

Fig. 3: Radiant flow image of fetal goiter at 37 weeks and 1 day of gestation. Abundant blood flow on both lobes, especially the left lobe

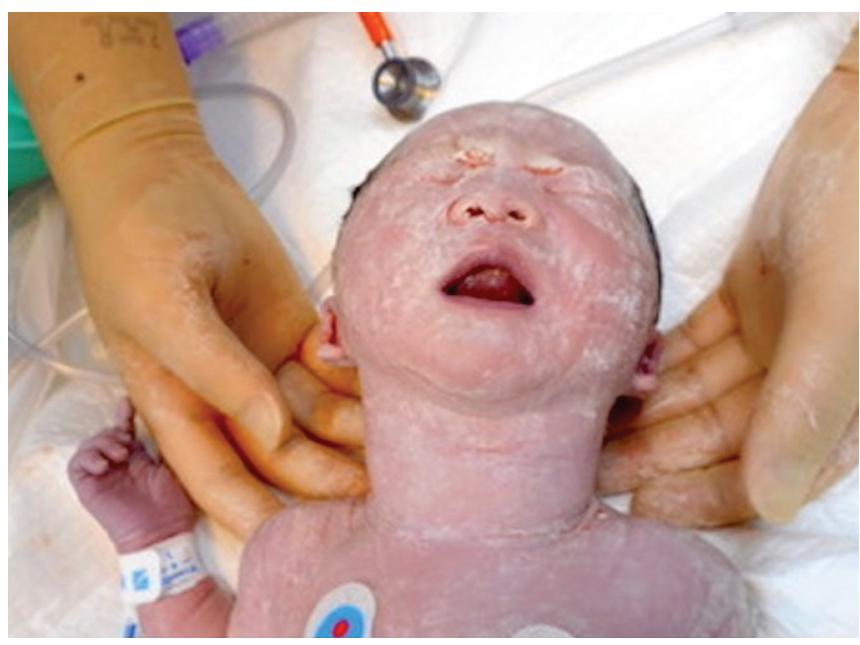

Fig. 5: Neonatal neck just after delivery. Mild swelling of the fetal neck is noted

great vessel abnormalities. ${ }^{7-11}$ Tenkumo et al. ${ }^{12}$ reported that HDlive flow showed the characteristic vascular pattern of fetal hepatic hemangioma. Therefore, the current study also suggests that this technique provides additional diagnostic information on the assessment of fetal peripheral vascular abnormality. Further studies involving a larger sample size are needed to assess the true usefulness of HDlive flow with STIC for the diagnosis of fetal peripheral vascular abnormalities.

\section{References}

1. Hata T, Kanenishi K, Nitta E, et al. HDlive Flow with HDlive silhouette mode in diagnosis of molar pregnancy. Ultrasound Obstet Gynecol 2018;52(4):552-554. DOI: 10.1002/uog.19106.

2. Hata T, AboEllail MAM, Sajapala S, et al. HDliveFlow in the assessment of fetal circulation. Donald School J Ultrasound Obstet Gynecol 2015;9(4):462-470. DOI: 10.5005/jp-journals-10009-1433.

3. Morine M, Takeda T, Minekawa R, et al. Antenatal diagnosis and treatment of a case of fetal goitrous hypothyroidism associated with high-output cardiac failure. Ultrasound Obstet Gynecol 2002;19(5):506-509. DOI: 10.1046/j.1469-0705.2002.00680.x. 
4. Huel C, Guibourdenche J, Vuillard E, et al. Use of ultrasound to distinguish between fetal hyperthyroidism and hypothyroidism on discovery of a goiter. Ultrasound Obstet Gynecol 2009;33(4):412-420. DOI: 10.1002/uog.6315.

5. Nath CA, Oyelese Y, Yeo L, et al. Three-dimensional sonography in the evaluation and management of fetal goiter. Ultrasound Obstet Gynecol 2005;25(3):312-314. DOI: 10.1002/uog.1863.

6. Marin RC, Bello-Munoz JC, Martinez GV, et al. Use of 3-dimensional sonography for prenatal evaluation and follow-up of fetal goitrous hypothyroidism. J Ultrasound Med 2010;29(9):1339-1343. DOI: 10.7863/jum.2010.29.9.1339.

7. AboEllail MAM, Kanenishi K, Tenkumo C, et al. Diagnosis of trncus arteriosus in first trimester of pregnancy using transvaginal fourdimensional color Doppler ultrasound. Ultrasound Obstet Gynecol 2015;45(6):759-760. DOI: 10.1002/uog.14868.

8. AboEllail MAM, Kanenishi K, Tenkumo $C$, et al. Four-dimensional power Doppler sonography with the HDlive silhouette mode in antenatal diagnosis of a right aortic arch with an aberrant left subclavian artery. JUltrasound Med 2016;35(3):661-663. DOI: 10.7863/ ultra.15.05047.

9. Yang PY, Sajapala S, Yamamoto K, et al. Antenatal diagnosis of idiopathic dilatation of fetal pulmonary artery with 3D power Doppler imaging. J Clin Ultrasound 2017;45(2):121-123. DOI: 10.1002/jcu.22367.

10. Ito M, AboEllail MAM, Yamamoto K, et al. HDlive Flow silhouette mode and spatiotemporal image correlation for diagnosing congenital heart disease. Ultrasound Obstet Gynecol 2017;50(3):411-415. DOI: 10.1002/uog.17519.

11. Hata T, Ito M, Nitta E, et al. HDlive Flow silhouette mode for diagnosis of ectopia cordis with a left ventricular diverticulum at 15 weeks' gestation. J Ultrasound Med 2018;37(10):2465-2467. DOI: 10.1002/ jum.14583.

12. Tenkumo C, Hanaoka U, AboEllail MAM, et al. HDlive Flow with HDlive silhouette mode in diagnosis of fetal hepatic hemangioma. Ultrasound Obstet Gynecol 2017;49(4):540-545. DOI: 10.1002/uog.16215. 